\title{
Incidence of distal radius fracture in a general population in southern Sweden in 2016 compared with 2001
}

\author{
M. Ali $^{1,4}$ (D) A. Eiriksdottir ${ }^{1} \cdot$ M. Murtadha ${ }^{2} \cdot$ A. Åkesson ${ }^{3} \cdot$ I. Atroshi $^{1,4}$ (D
}

Received: 20 August 2019 / Accepted: 6 January 2020 / Published online: 13 January 2020

(C) The Author(s) 2020

\begin{abstract}
Summary In this population-based study, we compared the incidence of distal radius fracture in 2016 with that in the same region's adult general population in 2001 using radiographs to identify fracture cases. We showed that the incidence decreased by $24 \%$ in 2016 compared with 2001 indicating an important development.

Introduction We conducted an epidemiological study on residents of northeastern Skåne in southern Sweden (population $182,000)$ to determine the overall incidence of distal radius fracture and the incidence according to age, sex, and fracture characteristics in the region's adult population during 2016, and to study the change in incidence in the same general population between 2001 and 2016 using wrist radiographs to identify fracture cases.

Methods Two orthopedic surgeons examined all wrist radiographs performed at the only two emergency hospitals in the study region to identify individuals, above 18 years of age, who sustained fracture of the distal radius during 2016. We used Poisson regression analysis adjusting for age, sex, and at-risk population to compare the incidence in 2016 with the incidence in 2001 , previously estimated using similar methodology.

Results The overall incidence in 2016 was 22 (95\% CI 20-25) per 10,000; the incidence in women was 34 (95\% CI 30 39 ) and in men was 10 (95\% CI 8-12) per 10,000. The overall incidence in 2016 was 0.76 (95\% CI $0.70-0.82)$ of the incidence in $2001(p<0.0001)$. The incidence in the 3 age groups $19-49,50-79$, and $\geq 80$ years was 0.91 (95\% CI, 0.69-1.20), 0.67 (95\% CI, 0.55-0.82), and 0.49 (95\% CI, 0.25-0.97) of the incidence in 2001, respectively.

Conclusion In a general population in Sweden, a statistically significant and clinically important decrease in the incidence of distal radius fracture occurred between 2001 and 2016, driven by lower incidence in individuals 50 years or older.
\end{abstract}

Keywords General population studies · Fracture incidence assessment $\cdot$ Fracture prevention · Osteoporosis $\cdot$ Radiology

Electronic supplementary material The online version of this article (https://doi.org/10.1007/s00198-020-05282-7) contains supplementary material, which is available to authorized users.

M. Ali

muhannedalhashimi@hotmail.com; muhanned.ali@skane.se

1 Department of Orthopedics, Kristianstad and Hässleholm Hospitals, Box 351, 28125 Hässleholm, Sweden

2 Department of Radiology, Kristianstad Hospital, Kristianstad, Sweden

3 Clinical Studies Sweden-Forum South, Skåne University Hospital, Lund, Sweden

4 Department of Clinical Sciences-Orthopedics, Lund University, Lund, Sweden

\section{Introduction}

Fracture of the distal radius is an important osteoporosisrelated fracture that mostly affects women after the age of 50 years [1]. The fracture may lead to substantial long-term disability and pain [2]. A distal radius fracture caused by low energy trauma is often the first indicator fracture in patients with osteoporosis, and the risk of sustaining further fractures increases after a distal radius fracture [3-5].

In previous studies conducted in Europe, North America, and Asia, the overall incidence rates of distal radius fracture have been shown to increase over time [6-8]. Other more recent studies have shown no change, or even a decrease, in the incidence [9-11]. During the last decade, programs for screening and treating osteoporosis have been implemented 
in health care, potentially affecting the incidence of distal radius fracture. Data about the prescription of osteoporosis medication (oral bisphosphonates) in Skåne County in southern Sweden showed that the number of defined daily dose (DDD), which is the average daily maintenance dose for a drug used for its main indication in adults [12], had more than doubled in women from 4.9 DDD/1000 women in 2000-2002 to $11.1 \mathrm{DDD} / 1000$ women in 2014-2016, and almost quadrupled in men from $0.66 \mathrm{DDD} / 1000$ men to $2.32 \mathrm{DDD} / 1000$ men [13].

The incidence of distal radius fracture has been shown to vary between different geographical areas, with higher incidence in Scandinavia than in other parts of Europe [14] and higher incidence in urban than in rural areas [15]. Because of this variation, the change in incidence over time would ideally be studied in the same population rather than comparing incidence rates across studies. Another difficulty in interpreting the results of previous studies is that most have solely used data from registers to identify fracture cases. Registers might not have high reliability and validity, and the diagnosis of wrist fractures by emergency physicians may lack adequate accuracy $[16,17]$. Few epidemiological studies have used radiographs as the gold standard in identifying fracture cases.

We have previously conducted a prospective populationbased study in the region of northeastern Skåne in southern Sweden, using radiographs to identify fracture cases, and found that the overall incidence of distal radius fractures in the adult population in 2001 was 26 per 10,000 [18].

The severity of distal radius fracture, with regard to whether the fracture involves the radiocarpal joint, has been studied in our previous population-based study and in other studies [18-20]. However, to our knowledge, no population-based study has yet addressed the changes in fracture severity over time in the same population. This is important because fracture severity often determines the choice of treatment (nonsurgical or surgical).

The aim of this population-based study was to estimate the overall incidence of distal radius fractures and the incidence according to age, sex, and fracture characteristics in the adult population of northeastern Skåne in Sweden during 2016 and compare the incidence to that estimated in the same population during 2001. Considering the increased use of osteoporosis medication in the study region, we hypothesized that the incidence of distal radius fracture would be lower in 2016 than it was in 2001.

\section{Materials and methods}

This is a population-based study conducted in the region of northeastern Skåne in southern Sweden. We identified all adults who sustained an acute distal radius fracture during the period of January 1 to December 31, 2016. The study region (population 182,000) has two hospitals (Kristianstad Hospital and Hässleholm Hospital), and these are the only health care facilities that manage acute radius fractures. The inclusion criteria for this study were acute fracture of the distal radius and age above 18 years. The exclusion criterion was residence outside the region at the time of fracture, according to the National Population Register. Patients with acute distal radius fracture seek the emergency departments of Kristianstad and Hässleholm Hospitals. These patients are prospectively registered in the department's register, by an orthopedic specialist or a resident, according to the International Classification of Diseases, Tenth Revision, Clinical Modification (ICD-10-CM) as S52.50, S52.51, S52.60, and S52.61. Our search strategy comprised two steps. In the first step, we conducted a search in our orthopedic department's patient register, using the ICD codes for distal radius fracture to identify fracture cases that fulfill the eligibility criteria. The radiographs (digital) of the identified fracture cases were examined to verify the diagnosis. In the second step, we examined all wrist radiographs performed for any reason during 2016 in the two hospitals in the study region to identify possible additional cases that might not have been registered in the orthopedic department's patient register. The second search was done in the radiology department's electronic database (common for the two hospitals), in which all performed radiographs are stored. We also reviewed the medical records of all the identified cases to ascertain that they fulfill the eligibility criteria. By this methodology, we could identify and verify all eligible cases with distal radius fracture in the study region during 2016. A few potentially eligible patients might not have sought health care (minor fracture) or sought and received treatment at hospitals outside the study region. That would however involve a very small number of patients.

One of the study researchers extracted from the medical records, demographic data including age, sex, fracture side, and fracture date. The anteroposterior and the lateral radiographs were examined by an orthopedic surgeon and a radiologist to confirm the diagnosis, to measure volar angulation and ulnar variance, and to classify the fracture according to the AO classification (type A, extra-articular; type B, partial intra-articular; type $\mathrm{C}$, complete intra-articular). The interrater reliability of the two examiners' measurements was evaluated with the intraclass correlation coefficient (ICC); ICC (95\% confidence interval $[\mathrm{CI}]$ ) for volar angulation was 0.965 (0.96-0.97), for ulnar variance was $0.866(0.84-0.89)$, and for AO classification was $0.80(0.75-0.83)$, indicating high reliability. The measures of one examiner were used in the analyses. As in our previous study [18], fractures with volar angulation of -5 to $20^{\circ}$ and/or ulnar variance of up to $1 \mathrm{~mm}$ were considered as nondisplaced or minimally displaced, and fractures with greater displacement were considered as displaced. 


\section{Statistical analysis}

For demographic data, we calculated mean, standard deviation, and range. To calculate the incidence, we obtained the age- and sex-specific general population data from Statistics Sweden (complete population data are reported for December 31 each year) [21]. We calculated the overall, age-specific (3 groups; $19-49,50-79$, and $\geq 80$ years) and sex-specific incidence rates with $95 \% \mathrm{CI}$. We also calculated incidence rates according to fracture AO type and displacement. The incidence rates were calculated as the number of individuals with fracture divided by the 2016 mid-year population and expressed as incidence per 10,000 persons. The 2016 mid-year population was calculated, using exactly the same method used to calculate the 2001 mid-year population, as (population on December 31, 2015 + population on December 31, 2016)/2. This was done for the total population and for the age- and sex-specific population subgroups. We compared the overall and the age-specific incidence rates in 2016 and 2001 adjusting for age (5 years group), sex, and at-risk population using Poisson regression analyses. A $p$ value of less than 0.05 was considered to indicate statistical significance. Statistical analysis was performed using the IBM SPSS Statistics for Windows, Version 24.0. (IBM Corp, Armonk, NY), and Stata Release 15 (Stata Corp College Station, TX).

\section{Results}

\section{Study population}

During 2016, an acute distal radius fracture was sustained by 314 adult residents of the study region (276 identified through the orthopedic department's patient register and additional 38 through review of all wrist radiographs). We also identified 22 fracture cases who were not residents of the study region and were thus excluded. The mean age of the 314 individuals included in this study was $66 \pm$ 19 years (range, 19-103 years); 245 (78\%) were women with a mean age of $68 \pm 18$ years (range, 19-103 years) and $69(22 \%)$ were men with a mean age of $57 \pm 21$ years (range, 20-93 years). The fracture involved the left wrist in 187 patients $(60 \%)$, the right wrist in $122(39 \%)$, and both wrists (bilateral) in $5(1.6 \%)$ patients. One patient had a subsequent new fracture of the same wrist during 2016. There were no missing data.

\section{Incidence}

The mid-year population above 18 years of age in the study region during 2016 was 142,214 . The overall incidence of distal radius fracture in 2016 was $22(95 \%$ CI, 20 to 25) per 10,000 persons. The incidence in women was 34 (95\% CI, 30 to 39 ) and in men was 10 (95\% CI, 8 to 12) per 10,000 . The women:men ratio of the incidence rate was $3.4: 1$. The overall incidence in 2016 was 0.76 (95\% CI, 0.70 to 0.82 ) of the incidence in $2001(p<0.0001)$. The age-specific incidence in 2016 was 0.91 (95\% CI, 0.69 to 1.20$)(p=$ $0.502)$ for individuals $19-49$ years, 0.67 (95\% CI, 0.55 to $0.82)(p<0.001)$ for individuals $50-79$ years, and 0.49 ( $95 \%$ CI, 0.25 to 0.97$)(p=0.042)$ for those $\geq 80$ years of the incidence in 2001, respectively.

The incidence in 2016 increased with age in both women and men (Table 1). Among individuals below 45 years of age, the incidence did not differ substantially between women and men (Fig. 1). After the age of 45 years, the incidence rate in women increased more rapidly with largest increase occurring after the age of 85 years. In men, the incidence increased gradually, with highest incidence of 36 per 10,000 persons seen in those older than 90 years.

\section{Fracture characteristics}

Of the 314 individuals with distal radius fracture in 2016, 163 (52\%) had type A (extra-articular), 28 (9\%) type B (partial intra-articular), and 123 (39\%) had type C (complete intraarticular) (Table 2) compared with 79\%, 5\% and $16 \%$, respectively, in 2001. The ratio of A:C fracture in 2016 was 1.3:1 compared with 4.9:1 in 2001. The incidence of type-A fracture during 2016 was 12 (95\% CI, 10 to 13) and of type-C fracture was 9 (95\% CI, 7 to 10$)$.

There were 197 (63\%) individuals with displaced fracture and $117(37 \%)$ with non-displaced or minimally displaced fractures (Table 3); the values among women were 162
Table 1 Incidence of distal radius fracture per 10,000 persons in the adult general population of northeastern Skåne in Sweden during 2016

\begin{tabular}{lllll}
\hline Sex & Age group (years) & Population & No. with fracture & Incidence (95\% CI) \\
\hline Women & $19-49$ & 33,165 & 33 & $10(7-14)$ \\
& $50-79$ & 31,536 & 147 & $47(39-55)$ \\
\multirow{4}{*}{ Men } & $80-$ & 6584 & 65 & $99(76-126)$ \\
& $19-49$ & 34,819 & 25 & $7(5-11)$ \\
& $50-79$ & 31,729 & 34 & $11(7-15)$ \\
& $80-$ & 4381 & 10 & $23(11-42)$ \\
\hline
\end{tabular}


Fig 1 Incidence of distal radius fracture in northeastern Skåne in Sweden during 2016 according to age group and sex. The curve for men ends at 94 years as no man above that age had a fracture during 2016
300

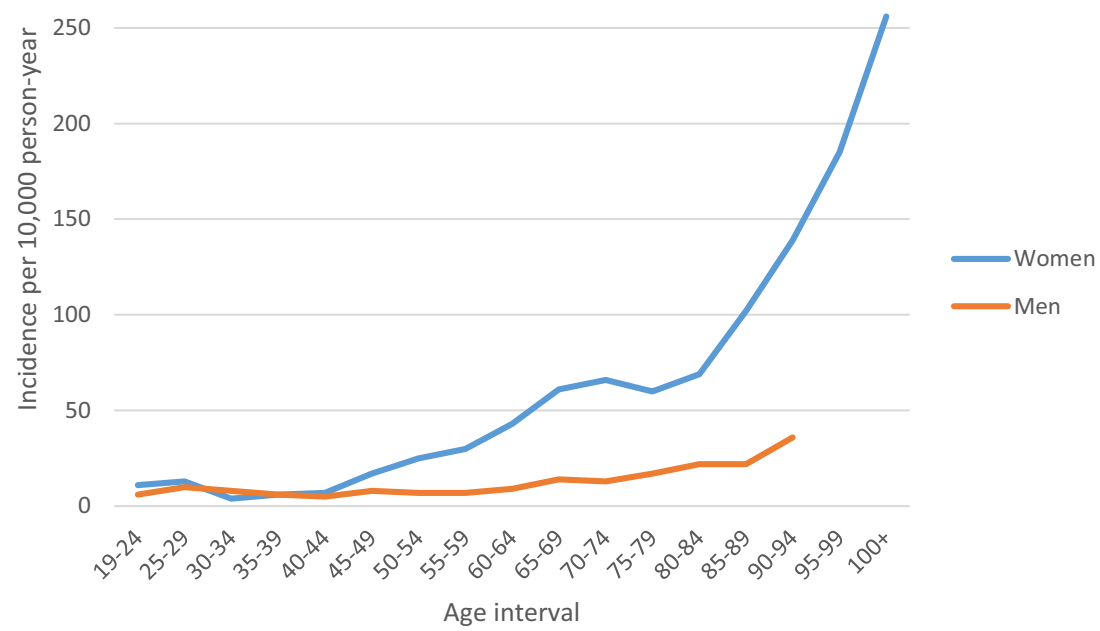

(66\%) and $83(34 \%)$, and among men were $36(52 \%)$ and 33 (48\%), respectively. The ratio of displaced:non-displaced fractures in 2016 was 1.7:1 compared with 1.9:1 in 2001.

\section{Discussion}

Our study showed that the overall incidence of distal radius fracture in the adult general population of a representative region in southern Sweden during 2016 was 22 (95\% CI 20 to 25$)$ per 10,000 persons. Adjusted for age, sex, and at-risk population, the incidence in 2016 was $24 \%$ lower than that in 2001 in the same general population. A recent study from Norway on acute distal radius fractures in one hospital's catchment area (suburban and urban areas in and outside Oslo) during the years 2010 and 2011 showed that the overall annual incidence among inhabitants aged 16 years or older was 19.7 (95\% CI 18.7-20.7) per 10,000 [11]. That incidence was lower than the incidence reported in 2 earlier Norwegian studies from Oslo (1-year study period in 1998-1999) [22] and from Bergen (1988) [23], respectively.

Our study compared the incidence of distal radius fracture over time in the same geographical region and used wrist radiographs to identify and verify fracture cases. Our results are in contrast to a register-based study from Skåne region in Sweden [24] that reported a significant increase in the incidence of distal forearm fracture from 1999 to 2010, in both men and women. Our results are also in contrast to a study from Taiwan that reported annual increase in the incidence of distal radius fracture between years 2000 and 2007 [25]. These studies were however based on register data only.

The decrease in the overall fracture incidence in 2016 compared with 2001 was due to a decrease in incidence at age of 50 years or older, while the incidence below 50 years remained almost unchanged. Similar trends have been observed previously in Norway, where the incidence of distal radius fracture in women at the age of 50-59 years in Oslo during a 1-year period in 1998-1999 had fallen markedly compared with 1979 [22]. In Iceland, the incidence in women aged 50-70 years was considerably lower in 2004 than in 1985 [26]. However, we have now shown that this decrease in incidence involves all individuals above the age of 50 years. These findings are important and might indicate the effect of osteoporosis treatment even in old age. Another explanation for the decrease in incidence could be that many elderly remain physically active leading to a better neuromuscular

Table 2 Incidence (per 10,000 persons) according to fracture type

\begin{tabular}{|c|c|c|c|c|c|c|c|c|}
\hline \multirow[t]{2}{*}{ Sex } & \multirow[t]{2}{*}{ Age group (years) } & \multirow[t]{2}{*}{ Population } & \multicolumn{2}{|c|}{ Type A } & \multicolumn{2}{|c|}{ Type B } & \multicolumn{2}{|c|}{ Type C } \\
\hline & & & $n$ & Incidence $(95 \% \mathrm{CI})$ & $n$ & Incidence $(95 \% \mathrm{CI})$ & $n$ & Incidence $(95 \% \mathrm{CI})$ \\
\hline \multirow[t]{3}{*}{ Women } & $19-49$ & 33,165 & 16 & $5(3-8)$ & 3 & $1(0.2-3)$ & 14 & $4(2-7)$ \\
\hline & $50-79$ & 31,536 & 78 & $25(20-31)$ & 5 & $2(1-4)$ & 64 & $20(16-26)$ \\
\hline & $80-$ & 6584 & 45 & $68(50-92)$ & 3 & $5(1-13)$ & 17 & $26(15-41)$ \\
\hline \multirow[t]{3}{*}{ Men } & $19-49$ & 34,819 & 10 & $3(1-5)$ & 8 & $2(1-5)$ & 7 & $2(1-4)$ \\
\hline & $50-79$ & 31,729 & 11 & $4(2-6)$ & 7 & $2(1-5)$ & 16 & $5(3-8)$ \\
\hline & $80-$ & 4381 & 3 & $7(1-20)$ & 2 & $5(1-17)$ & 5 & $11(4-27)$ \\
\hline
\end{tabular}


Table 3 Incidence (per 10,000 persons) according to fracture displacement

\begin{tabular}{|c|c|c|c|c|c|c|}
\hline \multirow[t]{2}{*}{ Sex } & \multirow[t]{2}{*}{ Age group (years) } & \multirow[t]{2}{*}{ Population } & \multicolumn{2}{|c|}{$\begin{array}{l}\text { Non-/minimally displaced } \\
\text { fracture }\end{array}$} & \multicolumn{2}{|c|}{ Displaced fracture } \\
\hline & & & $n$ & Incidence $(95 \% \mathrm{CI})$ & $n$ & Incidence $(95 \% \mathrm{CI})$ \\
\hline \multirow[t]{3}{*}{ Women } & $19-49$ & 33,165 & 15 & $5(3-8)$ & 18 & $5(3-9)$ \\
\hline & $50-79$ & 31,536 & 46 & $15(11-20)$ & 101 & $32(26-39)$ \\
\hline & $80-$ & 6584 & 22 & $33(21-51)$ & 43 & $65(47-88)$ \\
\hline \multirow[t]{3}{*}{ Men } & $19-49$ & 34,819 & 16 & $5(3-8)$ & 9 & $3(1-5)$ \\
\hline & $50-79$ & 31,729 & 15 & $5(3-8)$ & 19 & $6(4-9)$ \\
\hline & $80-$ & 4381 & 3 & $7(1-20)$ & 7 & $16(6-33)$ \\
\hline
\end{tabular}

coordination and improved bone mineral density with a lower fracture risk.

Although extra-articular fracture (AO type A) was the most common type (52\% of the distal radius fractures) in the study region during 2016, this was substantially lower in 2001 when type-A fracture accounted for $79 \%$ of the fractures. The proportion of type-C fracture increased from 16\% in 2001 to $39 \%$ in 2016. A similar observation has recently been made in Germany, where the proportion of type-A fractures was lower and of type-C fractures was higher than previously reported in the literature [27]. The higher incidence of type- $\mathrm{C}$ fracture and the lower incidence of type-A fracture compared with 2001 was seen in all age groups, not only in the elderly. Thus, the higher proportion of intra-articular fractures cannot be explained by increased life expectancy and the fact that many elderly are more active with higher risk of more severe wrist injury. One possible explanation of the higher proportion of type-C fractures could be the higher resolution of the modern, digital radiographs leading to more accurate classification. This theory is supported by the fact that the proportion of displaced fractures remained almost unchanged in 2016 as compared with 2001.

Our study has strengths and limitations. To our knowledge, no other studies have investigated the change in incidence of distal radius fracture during the last two decades in a welldefined geographic region using wrist radiographs as gold standard for identifying and verifying fracture cases. Besides, the composition of at-risk population remained unchanged in the study region (Online resource 1) [21].

One limitation is the possibility that an eligible individual may have sustained a minor fracture while being outside the study region and the injury was deemed, at the treating hospital, to not require further follow-up at our orthopedic department. This would probably involve only few cases and would only have minor influence on the incidence estimates. Besides, it would have similarly affected the incidence rates in 2001 and 2016. Thus, it would likely not affect the change in incidence. The incidence of distal radius fracture may be influenced by weather conditions, as lower temperatures increase risk of falls and fractures [28]. However, data about the daily temperatures during 2001 and 2016 in the study region showed that the mean temperature for days when fractures occurred did not differ substantially between the two study years (Online resource 2) [29]. Another limitation is that part of the methodology to identify fracture cases was not exactly the same in our current study and our previous study that estimated the incidence in 2001 [18]. The ICD-10 codes used in 2001 and 2016 were exactly the same, and we searched the department's patient register for distal radius fractures in both years in a similar fashion. In 2001, we examined the radiographs (non-digital) of all identified cases to verify the fractures, and in addition we searched all ICD-10 codes for forearm fracture and wrist sprain and examined the radiographs of these cases to find any distal radius fracture cases that might have been incorrectly coded. No digital radiographs were available in 2001, and therefore we did not examine all wrist radiographs performed at the two hospitals in 2001 as we did in 2016. However, this would imply possible underestimation of the incidence in 2001 and that the decrease in incidence shown in 2016 may even be larger.

We conclude that the incidence of distal radius fracture has decreased during the last two decades. This is an important development, and a similar trend might be expected in other osteoporosis-related fractures as hip fractures.

Funding information Open access funding provided by Lund University. The study was supported by an internal research grant from Region Skåne (FoU research grant). There was no source of external funding for this study.

\section{Compliance with ethical standards}

\section{Conflict of interest None.}

Ethical approval The study was approved by the Ethical Review Board of Lund University.

Open Access This article is licensed under a Creative Commons Attribution-NonCommercial 4.0 International License, which permits any non-commercial use, sharing, adaptation, distribution and reproduction in any medium or format, as long as you give appropriate credit to the original author(s) and the source, provide a link to the 
Creative Commons licence, and indicate if changes were made. The images or other third party material in this article are included in the article's Creative Commons licence, unless indicated otherwise in a credit line to the material. If material is not included in the article's Creative Commons licence and your intended use is not permitted by statutory regulation or exceeds the permitted use, you will need to obtain permission directly from the copyright holder. To view a copy of this licence, visit http://creativecommons.org/licenses/by-nc/4.0/.

\section{References}

1. Oyen J, Gjesdal CG, Brudvik C, Hove LM, Apalset EM, Gulseth $\mathrm{HC}$ et al (2010) Low-energy distal radius fractures in middle-aged and elderly men and women-the burden of osteoporosis and fracture risk: a study of 1794 consecutive patients. Osteoporos Int 21(7):1257-1267

2. Ali M, Brogren E, Wagner P, Atroshi I (2018) Association between distal radial fracture malunion and patient-reported activity limitations: a long-term follow-up. J Bone Joint Surg Am 100(8):633-639

3. Johnson NA, Stirling ER, Divall P, Thompson JR, Ullah AS, Dias JJ (2017) Risk of hip fracture following a wrist fracture-a metaanalysis. Injury 48(2):399-405

4. Van Staa TP, Leufkens HG, Cooper C (2002) Does a fracture at one site predict later fractures at other sites? A British cohort study. Osteoporos Int 13(8):624-629

5. Ahmed LA, Center JR, Bjornerem A, Bluic D, Joakimsen RM, Jorgensen L et al (2013) Progressively increasing fracture risk with advancing age after initial incident fragility fracture: the Tromso study. J Bone Miner Res 28(10):2214-2221

6. Bengner U, Johnell O (1985) Increasing incidence of forearm fractures. A comparison of epidemiologic patterns 25 years apart. Acta Orthop Scand 56(2):158-160

7. Melton LJ 3rd, Amadio PC, Crowson CS, O'Fallon WM (1998) Long-term trends in the incidence of distal forearm fractures. Osteoporos Int 8(4):341-348

8. Tsukutani Y, Hagino H, Ito Y, Nagashima H (2015) Epidemiology of fragility fractures in Sakaiminato, Japan: incidence, secular trends, and prognosis. Osteoporos Int 26(9):2249-2255

9. Wilcke MK, Hammarberg H, Adolphson PY (2013) Epidemiology and changed surgical treatment methods for fractures of the distal radius: a registry analysis of 42,583 patients in Stockholm County, Sweden, 2004-2010. Acta Orthop 84(3):292-296

10. Stirling ERB, Johnson NA, Dias JJ (2018) Epidemiology of distal radius fractures in a geographically defined adult population. $\mathrm{J}$ Hand Surg Eur 43(9):974-982

11. Solvang HW, Nordheggen RA, Clementsen S, Hammer OL, Randsborg PH (2018) Epidemiology of distal radius fracture in Akershus, Norway, in 2010-2011. J Orthop Surg Res 13(1):199

12. World Health Organization (2019) Defined daily dose (DDD). https://www.who.int/medicines/regulation/medicines-safety/ toolkit ddd/en/.

13. The Swedish eHealth Agency (2019) https://www. ehalsomyndigheten.se/other-languages/english/.

14. Ismail AA, Pye SR, Cockerill WC, Lunt M, Silman AJ, Reeve J et al (2002) Incidence of limb fracture across Europe: results from the European Prospective Osteoporosis Study (EPOS). Osteoporos Int 13(7):565-571
15. Omsland TK, Ahmed LA, Gronskag A, Schei B, Emaus N, Langhammer A et al (2011) More forearm fractures among urban than rural women: the NOREPOS study based on the Tromso study and the HUNT study. J Bone Miner Res 26(4):850-856

16. Aitken SA, Rodrigues MA, Duckworth AD, Clement ND, McQueen MM, Court-Brown CM (2012) Determining the incidence of adult fractures: how accurate are emergency department data? Epidemiol Res Int 2012:7

17. Bassgen K, Westphal T, Haar P, Kundt G, Mittlmeier T, Schober HC (2013) Population-based prospective study on the incidence of osteoporosis-associated fractures in a German population of 200, 413 inhabitants. J Public Health (Oxf) 35(2):255-261

18. Brogren E, Petranek M, Atroshi I (2007) Incidence and characteristics of distal radius fractures in a southern Swedish region. BMC Musculoskelet Disord 8:48

19. Bentohami A, Bosma J, Akkersdijk G, Dijkman B, Goslings J, Schep N (2014) Incidence and characteristics of distal radial fractures in an urban population in The Netherlands. Eur J Trauma Emerg Surg 40(3):357-361

20. Flinkkila T, Sirnio K, Hippi M, Hartonen S, Ruuhela R, Ohtonen P et al (2011) Epidemiology and seasonal variation of distal radius fractures in Oulu, Finland. Osteoporos Int 22(8):2307-2312

21. Statistics Sweden (2018) Population by region, marital status, age and sex. Year:1968-2018 http://www.statistikdatabasen.scb.se/ pxweb/en/ssd/START_BE_BE0101_BE0101A/BefolkningNy/

22. Lofthus CM, Frihagen F, Meyer HE, Nordsletten L, Melhuus K, Falch JA (2008) Epidemiology of distal forearm fractures in Oslo, Norway. Osteoporos Int 19(6):781-786

23. Hove LM, Fjeldsgaard K, Reitan R, Skjeie R, Sorensen FK (1995) Fractures of the distal radius in a Norwegian city. Scand J Plast Reconstr Surg Hand Surg 29(3):263-267

24. Jerrhag D, Englund M, Karlsson MK, Rosengren BE (2017) Epidemiology and time trends of distal forearm fractures in adults - a study of 11.2 million person-years in Sweden. BMC Musculoskelet Disord 18(1):240

25. Tsai CH, Muo CH, Fong YC, Lo WY, Chen YJ, Hsu HC, Sung FC (2011) A population-based study on trend in incidence of distal radial fractures in adults in Taiwan in 2000-2007. Osteoporos Int 22(11):2809-2815

26. Sigurdardottir K, Halldorsson S, Robertsson J (2011) Epidemiology and treatment of distal radius fractures in Reykjavik, Iceland, in 2004. Comparison with an Icelandic study from 1985. Acta Orthop 82(4):494-498

27. Sander AL, Leiblein M, Sommer K, Marzi I, Schneidmuller D, Frank J (2018) Epidemiology and treatment of distal radius fractures: current concept based on fracture severity and not on age. Eur J Trauma Emerg Surg:1-6. https://doi.org/10. 1007/s00068-018-1023-7

28. Johnson NA, Stirling E, Dias JJ (2018) The effect of mean annual temperature on the incidence of distal radial fractures. J Hand Surg Eur 43(9):983-987

29. Swedish Meteorological and Hydrological Institute (2018) Download meteorological observations. https://www.smhi.se/data/ meteorologi/ladda-ner-meteorologiska-observationer/\#param= airtemperatureInstant,stations $=$ all,stationid $=64030$. Accessed 2 November 2018

Publisher's note Springer Nature remains neutral with regard to jurisdictional claims in published maps and institutional affiliations. 